\title{
Validation of Land Fragmentation and Rural Sustainability Assessment Scale
}

\author{
Abba Saleh ${ }^{a}$, Mohammad Rafee Bin Majid ${ }^{b}$ \\ ${ }^{a, b}$ Faculty of the Built Environment and Surveying, Universiti Teknologi Malaysia, Malaysia.
}

Article History: Received: 11 January 2021; Accepted: 27 February 2021; Published online: 5 April 2021

\begin{abstract}
This study was conducted to assess the validity of land fragmentation and rural sustainability assessment scale (LFRSS). To achieve the purpose a cross-sectional survey design was adopted with a sample of 40 selected from local governments in Yobe State Nigeria. The instruments contained 71 items spread among the 3 constructs of land fragmentation, causes of land fragmentation and rural sustainability. The data collected was entered into Microsoft Excel 2016 and SPSS 25 was used for the Analysis. The scale was evaluated through content validity with experts and Reliability with Cronbach's Alpha technique. The results indicated that, the scale has substantial content validity and acceptable reliability values of 0.77 (land fragmentation), 0.74 (causes of land fragmentation) and 0.75 (rural sustainability). However, 8 items on the overall failed to satisfied the condition to be certified as valid and thus, entirely removed form the scale (4 in causes of land fragmentation and 4 in rural sustainability). Accordingly, with the satisfaction of measurement requirements by 63 items, it can be concluded that, the developed LFRSS validated in this study can be used to assess the extent of land fragmentation and rural sustainability in Yobe state Nigeria.
\end{abstract}

Keywords: Land Fragmentation, Rural Sustainability, Validity, Reliability, Cronbach’s Alpha.

\section{Introduction}

The effect of land as a resource to human is immeasurable. It is a limited, non-reproducible natural resource that is indispensable for the existence and upkeep of humanity and preservation of all universal ecosystems. It is, therefore, a form of wealth that is transferable from one generation to another. Globally, land as a resource, is one of the significant factors of production, whereas on the other hand worlds' population is increasing at an alarming rate thereby impacting on the processes of acquisition and the use of land which subsequently results in a phenomenon called land fragmentation. Fragmentation of land is noted to be a worldwide phenomenon (Demetriou, Stillwell, \&amp; See, 2012; Iheke, O. R. and Amaechi, 2015; Kadigi, et al., 2017).

Farmlands distribution according to equity principles, without first considering farm management aspects, the result is that the parcels which farmers received are either too small or poorly shaped. For instance, in length-towidth ratio. 0.5 to 2.5 ha is the average farmland size in some European countries, which has made it difficult for the implementation new production patterns or to utilise machinery and appropriate technologies (Chakwizira, Mashiri, Nyoni, \&amp; Mokonyama, 2013; Reinmann, Hutyra, Trlica, Olofsson, 2016). The occurrence of fragmented farmland holdings is one of the distinctive characteristic of less developed nations through their cultivation practices Nigeria inclusive. It is, therefore, a substantial impediment to the mechanisation of agriculture, causing various agricultural productivity inefficiencies and requires a substantial cost to improve its effects (Balogun, Akinyemi, \&amp; Adam, 2017). Kadigi, et al., (2017) Sikk \& Maasikamäe, (2015) asserted that globally, Land fragmentation poses numerous detrimental effects on agricultural mechanisation efficiency and productivity subsequently leading to abject poverty thereby affecting rural sustainability. Rural sustainability is a continuous search for development strategies to produce and maintain "healthy" rural communities in which economic, socio-cultural, political and environmental values are compatible and which respond to any imperatives in these dimensions, at least in the long run. It is thus fundamentally the same as "urban sustainability", only the differences in the type of environments present, population densities and activity bases yield differences in the way in handling the issues and solutions (Copus \& Lima, 2014; Boluk, Cavaliere \& Higgins-Desbiolles, 2019).

In Nigeria, the land is the most valued asset of most rural dwellers whose primary occupation is agriculture, and it employs over 80 per cent of the rural population (Ifegbesan, Rampedi, \&amp; Annegarn 2016; National Planning Commission 2013). Extant literature has expressed the concern of some scholars such as Fabiyi, (1978) and Oloyede, Ayedun, Oni and Ibisola, (2015) on the problems of the traditional land tenure system and land fragmentation. The assertion of the scholars concerning the problems of land tenure could be interpreted based on the duplicity of ownership of land with indirect excessive transaction costs. The challenges of land fragmentation in the state lead to the lingering widespread of poverty, high unemployment and rural-urban migration in the state. Additionally, grazing reserves areas and routes demarcated for animals are regularly facing encouragement by farmers, and this stimulates clashes between farmers and cattle breeders. Therefore, the challenges above constitute 
a significant threat to rural economic sustainability in the communities in the state (Drvenkar, Marosevic, \& Odak, 2017; Zemba, Umar, \& Binbol, 2018).

The socio-economic development of humankind is dependent on land as a central supporting focus. Land fragmentation is one of the main changes associated with lands uses and changes globally. In this process, land fragmentation as a result of land-use conversion from its original state for human use become perpetual and most at times irreversible. Human action transformation thereby exerts a further effect on land-use change and associated with land allocation and regulations. Johnson, et al., (2014); Apata (2017) posit that notwithstanding several positives originating from urbanisation just as in rural land fragmentation, a fast urbanising environment is facing increased resource insufficiency, environmental degradation, and rural land fragmentation. Rural dearth is a worldwide problem and has undoubtedly accentuated through growing global levels of unsustainable land use. It is a fact that globally, migration is prominent from rural to urban centres and as such the development capacities of rural communities are collapsing and threaten their sustainability and resilience. Therefore, there is a greater need to theoretically and practically to study relevant aspect of land fragmentation, land-use policies, and mechanisms which may benefit adaptations to the revolution of socio-economic development and strategic change (Apata, 2017; Theke \& Amaechi, 2015)

\section{Objective}

This study aims at evaluating the quality of validation of land fragmentation and rural sustainability assessment scale

\section{Methodology}

\subsection{The Research Instrument/Scale}

The instrument for this study is a constructed and validated questionnaire. The instruments titled 'Land Fragmentation and Rural Sustainability Scale (LFRSS)' was divided into four (4) sections; A-D. Section A contained information about the respondents Demographic Information, Section B contained items to measure respondent perception on land fragmentation situation, section $\mathrm{C}$ contained items to measure causes of land fragmentation and Section D contained items to measure Rural Sustainability. All the items were generated were developed using established procedures in the literature and the stakeholders' perspectives, who are specialist in the field of this study.

\subsubsection{Land Fragmentation Situation}

This section of the instruments contains items to measure respondent perception on land fragmentation situation. The developed instrument was structured to suit the current research on closed ended responses in different categories. The section contained 9 carefully selected items rated to assess land fragmentation situation in the study area. With the few modifications, the instrument was subjected to the content validity, construct validity and reliability. The report of construct validity and reliability are presented in this report.

\subsubsection{Causes of Land Fragmentation}

This section of the instruments contains items to measure the causes of land fragmentation. The developed instrument was structured to suit the current research on a closed ended with Likert-Type scale. This section consists of 27 carefully selected items rated on a 4 point Likert scale (NI=Not Influential, SI=slightly influential, $\mathbf{I}=$ Influential, VI=Very Influential). With the few modifications, the instrument was subjected to the content validity, construct validity and reliability. The report of construct validity and reliability are presented in this report

\subsubsection{Rural Sustainability}

This section of the instruments contains items to measure the Rural Sustainability aspect of this research. The developed instrument was structured to suit the current research on a closed ended with Likert-Type scale. The section consists of 35 carefully selected items rated on a 4 point Likert scale (Strongly Agree (SA), Agree (A), Disagree (D) and Strongly Disagree (SD). With the few modifications, the instrument was subjected to the content validity, construct validity and reliability. The report of construct validity and reliability are presented in this report. 


\subsection{Participants}

To achieve the construct validity and the reliability of the questionnaire a pilot test was conducted, a sample of forty (40) respondents participated in the pilot testing. The sample size comprises male and female in a selected local government in Yobe State Nigeria. According to Baker (1994) a sample size of 10-20\% of the actual sample size for the study is considered as a reasonable number to participate in a pilot study.

\subsection{Content Validity of the Scale}

An instrument is said to be valid if it essentially measures what it is intended to measure. The content validity of the scale (Land Fragmentation and Rural Sustainability Scale) was content validate by 2 professional researchers in geography and environmental sciences as well as one other expert in related behavioural research (measurement and evaluation) for proper scrutiny. The experts validated the instruments in terms of clarity of language, ambiguity of the statement, relevance to the topic and appropriateness of the items. After scrutinizing the instruments some constructive suggestions and corrections which were made by the experts were effected before producing the final draft of the instruments.

\subsection{Administration of the Scale}

The content validated and modifed final draft of the scale was administered to the sample by the researcher after given specific instructions for the survey with the help of some residents in the selected areas. The questionaire were retrieved directly, scored, entered and used as data in this pilot study.

\subsection{Data Analysis}

To examine the internal consistency reliability of the research instrument in this study, the data collected from the pilot testing were analysed using SPSS 25 to conduct test of reliability of the instrument using Item-Total Statistics with Cronbach's Alpha coefficient. The results of the analysis provide a preliminary information on the suitability or otherwise of the research instrument

\section{Results}

\subsection{Summary Statistics}

The Scale reliability was used estimate the reliability of the 'Land Fragmentation and Rural Sustainability Survey Questionnaire (LFRSSQ)'. The summary statistics is the descriptive information generated using descriptive statistical analyses. Summary statistics are presented on Table 1. The results show Mean, Minimum, Maximum and Variance.

Table 1. Summary of Item Statistics

\begin{tabular}{|c|c|c|c|c|c|}
\hline Construct & Mean & Minimum & Maximum & Variance & $\mathrm{N}$ of Items \\
\hline Land Fragmentation & 4.30 & 3.93 & 4.60 & 0.09 & 9 \\
\hline Causes of Land Fragmentation & 3.48 & 2.49 & 3.97 & 0.09 & 25 \\
\hline Rural Sustainability & 3.50 & 2.95 & 3.95 & 0.06 & 35 \\
\hline
\end{tabular}

\subsection{Item-Total Statistics (Reliability/Internal Consistency)}

The results of the scale reliability analysis were conducted using item-total statistics with the Cronbach's Alpha coefficient. The analyses were run in two different stages: (i) Initial, which was obtained at the first stage of the validation that include all items including the poor ones. (ii) Modified which were obtained after removing the poor items that are not contributing to the overall reliability of the instruments. The results are presented in the following order:

\section{a) Land Fragmentation Situation (Initial)}

The result of the analysis as presented in Table 2 revealed the items' Cronbach's Alpha reliability coefficients of 0.731 . This parameter is considered satisfactory reliability because according to Hair, Anderson, Tatham \& Black (1995) and Cohen et al. (2010), a Cronbach's alpha scale of at least 0.70 is acceptable for the internal 
consistency reliability of the items and can therefore be accepted for study's purpose. These criteria served as the guidelines in interpreting the internal consistency-reliability coefficients in this research.

Table 2. Reliability Statistics

\begin{tabular}{ccc}
\hline Cronbach's Alpha & Cronbach's Alpha Based on Standardized Items & N of Items \\
\hline 0.731 & 0.767 & 9 \\
\hline
\end{tabular}

As established by the result of analysis based on reliability statistics, the Land Fragmentation sub-scale showed that, all the 9 items are retained and are to be used in the final draft of the questionnaire. The item total statistics presented in Table 3 shows no need of deleting any of the 9 items since the Cronbach's Alpha value is adequate for the entire items.

Table 3. Item-Total Statistics

\begin{tabular}{|c|c|c|c|c|}
\hline Item & $\begin{array}{c}\text { Scale Mean if Item } \\
\text { Deleted }\end{array}$ & $\begin{array}{c}\text { Scale Variance if Item } \\
\text { Deleted }\end{array}$ & $\begin{array}{l}\text { Corrected Item-Total } \\
\text { Correlation }\end{array}$ & $\begin{array}{c}\text { Cronbach's Alpha if Item } \\
\text { Deleted }\end{array}$ \\
\hline$\overline{\mathrm{LF} 1}$ & 34.12 & 12.728 & .420 & .711 \\
\hline LF2 & 34.27 & 11.846 & .372 & .714 \\
\hline LF3 & 34.15 & 12.079 & .544 & .693 \\
\hline LF4 & 34.15 & 12.182 & .422 & .706 \\
\hline LF5 & 34.12 & 12.728 & .420 & .711 \\
\hline LF6 & 34.72 & 11.692 & .429 & .703 \\
\hline LF7 & 34.75 & 11.064 & .417 & .707 \\
\hline LF8 & 34.80 & 11.036 & .350 & .727 \\
\hline LF9 & 34.70 & 10.933 & .464 & .697 \\
\hline
\end{tabular}

\section{b) Causes of Land Fragmentation (Initial and Modified)}

The result of the analysis as presented in Table 4 revealed the items' Cronbach's Alpha reliability coefficients of 0.686 at the initial stage, the result showed unsatisfactory parameter and therefore some items we recommended for deletion (See Appendix). The analysis was run after removing the 4 poor items (Item1, 3, 23 and 24).

The new reliability coefficient after removing the 4 items is presented in Table 5, the items' Cronbach's Alpha reliability coefficients became 0.740 after modification. This parameter $(0.740)$ is considered satisfactory reliability because according to Hair, Anderson, Tatham \& Black (1995) and Cohen et al. (2010), a Cronbach's alpha scale of at least 0.70 is acceptable for the internal consistency reliability of the items and can therefore be accepted for study's purpose. These criteria served as the guidelines in interpreting the internal consistencyreliability coefficients in this research.

Table 4. Reliability Statistics (Initial)

\begin{tabular}{|c|c|c|}
\hline Cronbach's Alph & aCronbach's Alpha Based on Standardized ItemsI & $\mathrm{N}$ of Items \\
\hline 0.686 & 0.697 & 27 \\
\hline & Table 5. Reliability Statistics (Modified) & \\
\hline Cronbach's Alpha & Cronbach's Alpha Based on Standardized Items & $\mathrm{N}$ of Items \\
\hline .740 & 0.728 & 23 \\
\hline
\end{tabular}

As established by the result of analysis based on reliability statistics showed that, the Causes of Land Fragmentation sub-scale showed that, 23 out of 27 items are to be retained in the final draft of the scale. The item total statistics presented in Table 6 revealed that, no need of further deletion of any items among the remaining 23 since the Cronbach's Alpha value is sufficient for the entire items. 
Table 6. Item-Total Statistics

\begin{tabular}{|c|c|c|c|c|}
\hline Item & $\begin{array}{l}\text { Scale Mean if Item } \\
\text { Deleted }\end{array}$ & $\begin{array}{c}\text { Scale Variance if Item } \\
\text { Deleted }\end{array}$ & $\begin{array}{c}\text { Corrected Item-Total } \\
\text { Correlation }\end{array}$ & $\begin{array}{c}\text { Cronbach's Alpha if Item } \\
\text { Deleted }\end{array}$ \\
\hline$\overline{\text { CLF2 }}$ & 78.51 & 32.625 & .363 & .725 \\
\hline CLF4 & 77.74 & 32.985 & .268 & .735 \\
\hline CLF5 & 77.72 & 31.682 & .464 & .716 \\
\hline CLF6 & 77.82 & 34.730 & .123 & .748 \\
\hline CLF7 & 77.13 & 37.220 & -.106 & .748 \\
\hline CLF8 & 77.03 & 36.868 & .001 & .742 \\
\hline CLF9 & 77.08 & 36.336 & .149 & .739 \\
\hline CLF10 & 777.31 & 33.903 & .403 & .725 \\
\hline CLF11 & 77.28 & 34.050 & .321 & .729 \\
\hline CLF12 & 277.51 & 34.414 & .187 & .740 \\
\hline CLF13 & 777.33 & 34.175 & .295 & .731 \\
\hline CLF14 & 177.38 & 33.927 & .297 & .731 \\
\hline CLF15 & 777.33 & 35.018 & .184 & .739 \\
\hline CLF16 & 577.38 & 35.190 & .142 & .742 \\
\hline CLF17 & 777.51 & 31.941 & .544 & .711 \\
\hline CLF18 & 377.46 & 31.939 & .625 & .708 \\
\hline CLF19 & 77.64 & 31.605 & .694 & .704 \\
\hline CLF20 & 977.46 & 32.781 & .409 & .722 \\
\hline CLF21 & 177.64 & 32.394 & .416 & .721 \\
\hline CLF22 & 277.51 & 35.730 & .098 & .744 \\
\hline CLF25 & 577.46 & 35.992 & .075 & .745 \\
\hline CLF26 & 677.54 & 34.308 & .265 & .733 \\
\hline CLF27 & 777.21 & 35.746 & .166 & .738 \\
\hline
\end{tabular}

\section{c) Rural Sustainability}

The result of the analysis as presented in Table 7 revealed the items' Cronbach's Alpha reliability coefficients of 0.669 at the initial stage, the result showed unsatisfactory parameter and therefore some items we recommended for deletion (See Appendix). The analysis was run after removing the 4 poor items (Item5, 10, 11 and 12).

The new reliability coefficient after removing the 4 items is presented in Table 8, the items' Cronbach's Alpha reliability coefficients became 0.726 after modifications. This parameter $(0.726)$ is considered satisfactory reliability because according to Hair, et. al (1995) and Cohen et al. (2010), a Cronbach's alpha scale of at least 0.70 is acceptable for the internal consistency reliability of the items and can therefore be accepted for study's purpose. These criteria served as the guidelines in interpreting the internal consistency-reliability coefficients in this study.

Table 7. Reliability Statistics (initial)

\begin{tabular}{cc}
\hline Cronbach's Alpha Cronbach's Alpha Based on Standardized Items N of Items \\
0.669 \\
0.696
\end{tabular}

Table 5. Reliability Statistics (Modified)

\begin{tabular}{lll}
\hline Cronbach's Alpha & Cronbach's Alpha Based on Standardized Items & N of Items \\
\hline 0.726 & 0.749 & 31 \\
\hline
\end{tabular}


Based on the result of analysis based on reliability statistics showed that, the Rural Sustainability sub-scale showed that, 31 out of the 35 items are to be retained for inclusion in the final draft of the questionnaire. The item total statistics presented in Table 9 revealed that, no need of further deletion of any items among the remaining 31 since the Cronbach's Alpha value is sufficient for the entire items.

Table 9. Item-Total Statistics

\begin{tabular}{|c|c|c|c|c|}
\hline Item & $\begin{array}{l}\text { Scale Mean if Item } \\
\text { Deleted }\end{array}$ & $\begin{array}{c}\text { Scale Variance if Item } \\
\text { Deleted }\end{array}$ & $\begin{array}{c}\text { Corrected Item-Total } \\
\text { Correlation }\end{array}$ & $\begin{array}{c}\text { Cronbach's Alpha if Item } \\
\text { Deleted }\end{array}$ \\
\hline $\mathrm{RS} 1$ & 105.32 & 51.661 & .059 & .728 \\
\hline $\mathrm{RS} 2$ & 105.37 & 52.292 & -.038 & .732 \\
\hline RS3 & 105.25 & 51.218 & .210 & .723 \\
\hline RS4 & 105.27 & 51.230 & .253 & .722 \\
\hline RS6 & 105.60 & 51.785 & .003 & .733 \\
\hline RS7 & 105.57 & 50.456 & .110 & .728 \\
\hline RS8 & 105.60 & 50.862 & .072 & .731 \\
\hline RS9 & 105.57 & 50.046 & .188 & .723 \\
\hline RS13 & 106.05 & 51.177 & .023 & .737 \\
\hline RS14 & 106.25 & 49.679 & .123 & .730 \\
\hline $\mathrm{RS} 15$ & 105.60 & 49.477 & .200 & .722 \\
\hline RS16 & 105.62 & 49.163 & .228 & .721 \\
\hline RS17 & 105.62 & 47.112 & .475 & .705 \\
\hline RS18 & 106.02 & 49.769 & .117 & .731 \\
\hline RS19 & 106.02 & 49.769 & .117 & .731 \\
\hline RS20 & 105.62 & 47.266 & .526 & .703 \\
\hline RS21 & 105.60 & 47.323 & .522 & .704 \\
\hline RS22 & 105.80 & 47.241 & .495 & .704 \\
\hline $\mathrm{RS} 23$ & 105.65 & 46.592 & .500 & .702 \\
\hline RS24 & 105.72 & 46.974 & .435 & .706 \\
\hline $\mathrm{RS} 25$ & 105.65 & 50.900 & .105 & .727 \\
\hline RS26 & 105.65 & 50.849 & .099 & .728 \\
\hline RS27 & 105.82 & 49.635 & .253 & .719 \\
\hline RS28 & 105.65 & 47.618 & .395 & .709 \\
\hline RS29 & 105.82 & 48.353 & .291 & .716 \\
\hline RS30 & 105.70 & 48.779 & .344 & .714 \\
\hline RS31 & 105.72 & 48.461 & .331 & .714 \\
\hline RS32 & 105.72 & 48.974 & .298 & .716 \\
\hline RS33 & 105.65 & 48.849 & .367 & .713 \\
\hline RS34 & 105.72 & 48.974 & .298 & .716 \\
\hline RS35 & 105.70 & 48.779 & .344 & .714 \\
\hline
\end{tabular}

\section{Conclusion}

In most cases, land fragmentation is a major inhibiting factor that affects rural sustainability. However, an indepth study of the relationship between land fragmentation and the rural sustainability of the rural communities in Nigeria is neither determined nor fully documented. Thus, this pilot study provides the validation report of ' $\underline{L}$ and Fragmentation and Rural Sustainability Survey Questionnaire (LFRSSQ)' that is proposed to be used to ascertain the extent and effect of land fragmentation on rural sustainability in Yobe state, Nigeria. Therefore, the results of the validity and reliability studies shows that, based on the established standards the instrument is valid and reliable and can be considered as a valid measuring instrument to collect relevant data in the present study.

\section{References}

1. Demetriou, D., Stillwell, J., \& See, L. (2012). Land consolidation in Cyprus: why is an integrated planning and decision support system required? Land use policy, 29(1), 131-142.

2. Iheke, O.R., \& Amaechi, E.T. (2015). Effect of land fragmentation on smallholders' productivity in Imo State, Nigeria. International Journal of Agricultural Science, Research and Technology in Extension and Education Systems, 5(3), 195-201.

3. Kadigi, R.M., Kashaigili, J.J., Sirima, A., Kamau, F., Sikira, A., \& Mbungu, W. (2017). Land fragmentation, agricultural productivity and implications for agricultural investments in the Southern 
Agricultural Growth Corridor of Tanzania (SAGCOT) region, Tanzania. Journal of development and agricultural economics, 9(2), 26-36.

4. Reinmann, A.B., Hutyra, L.R., Trlica, A., \& Olofsson, P. (2016). Assessing the global warming potential of human settlement expansion in a mesic temperate landscape from 2005 to 2050. Science of the Total Environment, 545, 512-524.

5. Lanckriet, S., Adgo, E., \& Nyssen, J. (2015). Book of abstracts Tropi Lakes 2015: Tropical lakes in a changing environment: water, land, biology, climate and humans.

6. Balogun, O.L., \& Akinyemi, B.E. (2017). Land fragmentation effects on technical efficiency of cassava farmers in South-West geopolitical zone, Nigeria. Cogent Social Sciences, 3(1), 1387983.

7. Sikk, K., \& Maasikamäe, S. (2015). Spatial properties of large agricultural landholdings of Estonia. In Proceedings of the 2015 International Conference 'Economic Science for Rural Development, 28, 3949.

8. Copus, A.K., \& Lima, P.D. (2014). Introduction: from rural development to rural territorial cohesion. In Territorial Cohesion in Rural Europe, 27-34.

9. Boluk, K.A., Cavaliere, C.T., \& Higgins-Desbiolles, F. (2019). A critical framework for interrogating the United Nations Sustainable Development Goals 2030 Agenda in tourism.

10. Ifegbesan, A.P., Rampedi, I.T., \& Annegarn, H.J. (2016). Nigerian households' cooking energy use, determinants of choice, and some implications for human health and environmental sustainability. Habitat International, 55, 17-24.

11. National Planning Commission. (2013). National development plan vision 2030.

12. Fabiyi, Y.L., \& Adegboye, R.O. (1978). The changing outlook of young farmers to land tenure in Nigeria: Implications for agricultural development. African Journal of Agricultural Sciences, 5(1).

13. Oloyede, S.A., Ayedun, C.A., Oni, A.S., \& Ibisola, A.S. (2015). Challenges of the Urban sector in Nigeria: The way forward. Civil and Environmental Research, 7(1), 84-88.

14. Drvenkar, N., Marosevic, K., \& Odak, A. (2017). Improvement of the National Strategic Planning System-Dreams and Reality. In Drvenkar, N., Marošević, K, Odak, A. Improvement of the national strategic planning system-dreams and reality, 25th International Scientific Conference on Economic and Social Development-XVII International Social Congress (ISC-2017)-Moscow, 30-31.

15. Zemba, A.A., Umar, Y., \& Binbol, N.L. (2018). Climatic information as evidence of desertification processes in northern Yobe State, Nigeria: Implications for agriculture and ecosystem. Global Journal of Pure and Applied Sciences, 24(1), 117-124.

16. Johnson, I.U., Hula, M.A., Ebong, M.S., \& Lazarus, L.M. (2014). Land Fragmentation and Crop Production: Evidence from the Rural Communities in GAAV District, Konshisha LG Area of Benue State, Nigeria. International Journal of Innovative Research and Development, 3(10), 116-122.

17. Apata, T.G. (2017). Exploration of public spending and gross domestic product's growth in agricultural sector: comparative analysis of Nigerian and Malaysian agricultural sector (1970-2010). African Journal of Economic and Sustainable Development, 6(2-3), 119-137. 